\title{
ANDRÉS SÁNCHEZ ROBAYNA: EL LIBRO, TRAS LA DUNA. DIÁLOGOS CON JOSÉ ÁNGEL VALENTE E YVES BONNEFOY
}

\author{
Claudie TERRASSON \\ Université Paris-Est-Marne-la-Vallée (UPEM) \\ claudie.terrasson@u-pem.fr
}

Déchirer le voile des conceptualisations à jamais abstraites...

Yves Bonnefoy (cit. en Sánchez Robayna, 2012: 12).

\section{$\mathbf{T}$} res poetas, tres críticos, tres traductores

La ocurrencia de reunir en un mismo estudio a Bonnefoy, Sánchez Robayna y Valente ${ }^{1}$ no extrañará a quienes conocen las obras señeras de estos poetas, críticos y traductores. Pese a ello, se añadirán unas explicaciones previas. Como lo postuló aforísticamente el propio Sánchez Robayna: «Comparar es, en efecto, tan inevitable como necesario» (Sánchez Robayna, 1999: 34). En rigor, al escribir esto, el crítico pensaba más en mostrar la complejidad de la literatura, entendida como un entramado de «yuxtaposiciones, contraposiciones y superposiciones» (Sánchez Robayna, 1999: 35). Proceden las citas de un artículo en que Sánchez Robayna analiza un libro de Claudio Guillén dedicado a la literatura europea con el enfoque de superar «la resbaladiza noción de lo literario nacional» (Ibíd.) echando puentes entre culturas y lenguas. Sus afirmaciones parecen anticipar este estudio y en verdad, esbozan su propósito. Se tratará aquí de descubrir las convergencias que puedan surgir de una lectura que combine y aúne las obras poéticas y teóricas de estos tres creadores que han sabido abrirse a la alteridad. En el campo de la poesía, se ilustrará por la elección del corpus robayniano: la edición bilingüe del poemario El libro, tras la duna que se publicó en Francia, con una nutrida introducción del traductor, el catedrático de literatura española contemporánea, Claude Le Bigot. Amén del intérés que en sí ya supone esta traducción bastará con decir que la edición ofrece un prefacio redactado por el propio Yves Bonnefoy para comprender que ello ha sido determinante a la hora de elegir un corpus. Además tal libro funciona como un gozne en la obra robayniana por constituir un momento de relectura de la obra anterior, es «simple y

\footnotetext{
${ }^{1}$ Andrés Sánchez Robayna es uno de los críticos valentianos más pertinentes y fue quien editó las Obras Completas de Valente en Galaxia Gutenberg (2006-2008), después de otras varias ediciones.
} 
llanamente reescritura. [...] No es que se haya agotado la lectura del mundo, todo lo contrario: ahora comienza» (Ruiz Casanova, 2012: 49).

Otro reconocido estudioso valentiano, Claudio Rodríguez Fer reúne a José Ángel Valente con Yves Bonnefoy y Andrés Sánchez Robayna al introducir y comentar el libro que compila las traducciones que hizo Valente, Cuaderno de versiones (Valente, 2002). Después de dedicar un comentario a la traducción valentiana de dos odas de John Keats, con su correspondiente publicación en 1976 por La Ilustración Poética Española e Iberoamericana, Rodríguez Fer precisa lo siguiente:

Posteriormente, en 1997, la segunda de ella fue reeditada en el libro Oda a una urna griega. Traducción colectiva del Taller de Traducción literaria de la Universidad de la Laguna, junto a muchas versiones a diversas lenguas occidentales -a veces también debidas a creadores, como Julio Cortázar, Augusto de Campos o Yves Bonnefoy- de «uno de los textos centrales de la tradición poética de occidente» al decir del prologuista, Andrés Sánchez Robayna (Rodríguez Fer, 2002: 13).

El comentario apunta claramente los cruces y lazos entre los tres poetas-traductores; de hecho, comparten ellos idénticos compromisos con el quehacer poético, el cual abarca tanto la vertiente de la traducción (que aquí no se abordará en profundidad por falta de tiempo ${ }^{2}$ ) como la vertiente crítica o lírica que se desarrollará más. Debe simplemente subrayarse que siendo los tres reconocidos traductores de poesía, no es de extrañar que se encuentren dialogando con la tradición poética y mediante dicha actividad de traducción dialogando entre ellos. Harto conocido es que Bonnefoy tradujo de modo predilecto a los poetas ingleses (Keats, en primer lugar) y, sus versiones de Shakespeare, con prólogos esclarecedores, constituyen referencias imprescindibles. Fue él un traductor «literario», por decirlo con palabras de Rodríguez Fer, lo mismo que Valente como ya se ha visto con Cuaderno de versiones; en cuanto a Sánchez Robayna, se le debe la creación del Taller de Traducción Literaria dedicado a la traducción literaria en la universidad de La Laguna, y aquí hace falta mencionar el volumen De Keats a Bonnefoy realizado por el Taller en 2006, siendo además otro ejemplo de entrecruzamiento entre los poetas de este estudio. Actividades y preocupaciones comunes pues a los tres poetas que ya dicen la voluntad, cuando no la fuerte necesidad interna ${ }^{3}$, de dialogar

2 Esta vertiente se merecería un estudio en sí por ser el siglo XX «el siglo de la traducción», se caracteriza verdaderamente por el auge de las traducciones hechas por poetas como se precisa a continuación: «[...] en la segunda mitad de la centuria el interés de los poetas por el fenómeno de la traducción poética ha hecho que no pueda, en verdad, llevarse a cabo un análisis de la poesía hispánica de ese periodo sin calibrar la función y el significado de las traducciones de poesía realizadas en ese marco cronológico» (Milán, Sánchez Robayna, Valente, Varela, 2000: 30). Digamos que este ejercicio mediante la inmersión en la alteridad poética y el crear una versión de otra palabra, encierra y permite entre otras muchas cosas un conocimiento de la propia poesía. Para el lector, las traducciones hasta sirven de introducción y guía para entrar en la poética propia del traductor como lo expone Jordi Doce hablando de Valente: «Valente tradujo siempre aquello que podía servirle en su intento de explorar su propio universo poético hasta el punto de que sus traducciones ofrecen un correlato de la evolución de su propia poesía» (Doce, 2013: 90). Sería interesante interrogarse acerca del papel que ha desempeñado la creación por Robayna del Taller de Traducción Literaria de la Universidad de la Laguna respecto a su propia escritura poética. Ruiz Casanova afirma con tino que «la pulsión lectora (y traductora) cuenta, y mucho, en sus virajes, en los caminos hallados, y también en los desechados» (Ruiz Casanova, 2012: 35).

${ }^{3}$ En el sentido que le dio Rilke a la expresión en la primera de las diez cartas que le mandó «a un joven poeta» entre 1903 y 1908: «Une œuvre d'art est bonne quand elle est née de la nécessité» (Rilke, 1929: 10). Rápidamente recordaré que estas cartas ofrecen mucho interés por su modernidad en la concepción del quehacer poético y de la creación. Rilke insiste mucho en la condición exílica del creador, en su necesaria soledad tal como lo hace Valente tanto en sus poemas como en sus ensayos; también le aconseja Rilke a su corresponsal saber estar atento y sensible a la presencia de las cosas 
con la tradición poética europea saliendo de los límites estrechos de un cuadro nacional siempre esterilizador.

Este trabajo se propone sacar a luz algunos de los cruces, los encuentros o las conexiones, o sea cuanto da fe de una manera de diálogo ${ }^{4}$ entre los tres creadores mediante sus obras respectivas, centrándose más según los momentos en Valente y Sánchez Robayna. Por los motivos evocados antes se tomará como referencia la edición bilingüe de El libro, tras la duna con el prefacio de Yves Bonnefoy; siendo teórico este prefacio, se citarán aquí preferentemente los ensayos del escritor francés, sin descartar por ello los poemas, sacados de distintos poemarios que van hasta Les planches courbes (2001b). Interesa comprobar cuáles son los elementos reflexivos similares. De Valente, se hablará de su obra poética y ensayística, partiendo de Fragmentos de un libro futuro (2000), libro póstumo. La primera publicación en España de El libro, tras la duna es del año 2002, o sea poco después de la publicación de Fragmentos. Pero más allá de la proximidad de fechas, llama la atención cierta coincidencia semántica entre los títulos, lo cual invita a interrogarlos y en este caso sí, compararlos.

\section{Libro y horizonte}

Lo más obvio es que recurren ambos a la palabra «libro» y por otra parte, estos títulos evocan un horizonte, geográfico para Sánchez Robayna, y temporal para Valente, sabiendo que lo geográfico en Robayna es también metáfora del discurrir del tiempo, portadora ésta de una historia personal y colectiva, cuando el título valentiano es denotativo del fluir. La elección de determinantes distintos («el» $\mathrm{y}$ «un») deja entrever ciertos matices diferenciales. Decir «el libro» supone que tanto el locutor como el lector comparten un mismo conocimiento del objeto, ya tienen un saber acerca de este objeto antes de verlo y casi lo pueden identificar, cuando el artículo indefinido «un» designa algo desconocido, desprovisto de identidad o rasgo precisos, algo difícil de visualizar o imaginar precisamente. Determinación que acerca en un caso, indeterminación que aleja y difumina en el otro.

En cuanto al horizonte espacial («la duna») evocado por Sánchez Robayna, es identificable en un primer momento como el de la insularidad canaria, es una forma familiar (como lo connota otra vez el determinante definido «la»), forma natural hecha de arena, por lo tanto movediza y cambiante según los vientos y la erosión ${ }^{5}$. La duna puede desempeñar una función doble, a la vez ocultar el

más humildes de la realidad, y particularmente las de la naturaleza. Remite eso tanto a los textos y poemas de Bonnefoy como a la poesía robayniana.

${ }^{4}$ Al hablar de «diálogo poético» me refiero a la expresión que emplea François Vezin, el traductor de Sein und Zeit de Heidegger publicado por Gallimard (1986). Aparece la formula en el texto «Deux langues, mises pli sur pli», que Vezin leyó para introducir una lectura poética de Essor que Peter Nim hizo el 7 de noviembre de 2001 para la asociación La palabra en archipiélago (traduzco) en Reims. En su texto, François Vezin precisa que el propio Heidegger se valió de tal expresión para definir cómo el poeta Georg Trakl se situaba respecto a los poetas franceses finiseculares Baudelaire, Rimbaud, Verlaine.

${ }^{5}$ Aunque en la obra anterior, el elemento natural y referencial evocado preferentemente se presenta como roca, piedra, losa, más que como duna, la arena aparece no obstante en varios poemas de Tinta por ejemplo. Con «la duna», se evoca el proceso por el que la piedra o la roca se deshacen, movimiento de deshacimiento como dijera Valente, hasta convertirse en arena. Cabe entender el término ‘duna' en su dimensión metafórica, y no solo referencial. 
libro a la vista pero también protegerlo. Sin embargo, el sintagma leído en su totalidad, El libro, tras la duna parece anunciar el libro como promesa y descubrimiento, como si el que dice tal frase ya supiera que el libro se encuentra tras la duna. Lo sitúa así en un futuro próximo. De futuro también se trata con el título valentiano: Fragmentos de un libro futuro privilegia de entrada un horizonte temporal al presentarle al lector, no un libro acabado, sino fragmentos, un conjunto de formas aparentemente sin terminar, sin ordenar, lo cual parece verse acentuado luego por el adjetivo «futuro» que aleja todavía más la posibilidad de conseguir un libro realizado y total. Sitúa pues el libro en un tiempo por venir, imposible de conocer a la par que se caracteriza por su dimensión de objeto inacabado, como si estuviera en trance de formación, en estado de work in progress; es como si perteneciera a una cadena infinita como puede ser la tradición concebida como un libro que no deja nunca de escribirse a lo largo del tiempo.

\section{Continuidad, unidad, fragmento}

Ambos libros recurren al fragmento. La crítica lo señaló de modo unánime a propósito de $\mathrm{El}$ libro, tras la duna: «se presenta como un largo poema unitario compuesto por 77 fragmentos» (Luján, 2003: 45). Igualmente Túa Blesa lo define como un «poema extenso, unitario en su división en fragmentos» (Blesa, 2004: 172). Si se estructura y unifica el libro alrededor de un eje temporalautobiográfico como lo precisa Blesa (lo abordaremos luego, pero sí es libro de educación o de aprendizaje a la manera de un Bildungsroman), no podemos dejar de observar por otra parte un elemento de tensión: la tensión que se produce entre los fragmentos de índole meditativa (que suelen ser breves) y los poemas narrativos, por lo general más extensos. Eso genera que la progresión del relato autobiográfico se vea regularmente ralentizada, eso sí nunca interrumpida, por las pausas meditativas y metapoéticas. Seguimos a un yo lírico que pasa alternativamente de la introspección al relato más factual, del tiempo íntimo al tiempo histórico o empírico. Hay que reconocer que esa variabilidad discursiva, rítmica, incluso tonal, no impide una forma de continuidad, y ésta se debe a la unidad creada por la voz del yo, hombre y poeta. Lo vemos sometido a fuerzas o pulsiones internas y externas, preguntas y dudas, exaltaciones y felicidades. La progresión cronológica y personal del yo dibuja, en rigor, en esta rememoración reflexiva un sentido evidente que le da al libro la forma de un diario. Quizás por eso la formulación El libro, tras la duna, invite a pensar que el yo lírico tiene plena conciencia del libro y de su existencia; ya lo contempla por anticipación como un todo casi acabado ya y completo, por eso lo anuncia como si la duna no fuera un obstáculo: «Verá formarse el libro, tras la duna» (Sánchez Robayna, 2012: 138).

Pese a ello, el futuro verbal y el empleo de la preposición recuerdan la precariedad y fragilidad del advenimiento. La imagen del libro es casi total y es en este 'casi' donde se encuentra lo poético, entre aparición fugaz, huida y desaparición. Este poema XXXV, narrativo y central en la estructura del poemario, resume el recorrido físico y personal que conduce del niño al joven intelectual, evoca este viaje espiritual y físico que lo lleva a la visión del libro. Importa que el libro surja ante el 
hombre que iba en pos de él, que se le aparezca como el término del caminar: se marca así que constituye el objeto final de una indagación la cual entonces adquiere visos de aprendizaje, hasta de iniciación a lo sagrado (metaforizado por la «nube del no saber» que remite a toda una tradición espiritual como lo han subrayado ampliamente los estudiosos). Por eso la crítica ha insistido en comentar que este poemario robayniano marcaba una etapa nueva. Ruiz Casanova lo califica de «libro de formación» diciendo que abre una tercera fase de la obra (Ruiz Casanova, 2012: 19). La precisión espacial («tras la duna») deja entender que el yo lírico está a punto de cruzar una forma de frontera para conseguir un conocimiento más. La isotopía del verbo «ver» declinado en varias formas a lo largo del poema, plasma la noción de descubrimiento y contemplación. Asociado al verbo «saber», dibuja un itinerario espiritual y humano, una experiencia de saber en la que prima lo sensible más que la razón: «En las arenas / verá su rastro. Y mirará las nubes». (Íbid.). Anticipando un punto que se desarrollará luego, diré que tal concepción del saber mediante lo sensible y el situar tal experiencia del saber en un entorno natural escueto y sencillo remiten al pensamiento de Bonnefoy, a su devoción «Aux orties et aux pierres» (Bonnefoy, 1982: 179). Muestran una similitud de postura que aúna lo sensible y lo natural con la creación. Cabría interrogarse acerca de los poemas breves que la crítica designa como fragmentos. Si ostentan formalmente brevedad (aunque tampoco sea ello un criterio suficiente del fragmento), llama la atención el que casi siempre queden en ellos elementos de narratividad, la presencia de referentes naturales, una dicción que se amolda a una voluntaria y aparente sencillez:

\author{
Recostado en la hierba, una luna de hilo \\ Colgada entre las nubes estelares \\ Me acompañaba. El prado \\ de oscura luz me asía. \\ La desplegada savia de la noche \\ Se ahondaba como sangre. ¡Y en mis venas, \\ Red negra, se espejaban los llantos y los latidos \\ de estrellas y de párpados en el cielo pletórico! (Sánchez Robayna, 2012: 108)
}

Nos propone Sánchez Robayna un tipo de fragmento que difiere del de Valente por la evocación de una situación referencial, por la presencia de un entorno que parece identificable (casi familiar en la estrofa inicial) y la del yo lírico expresando su sensibilidad. Son estos elementos combinados a la sencillez sintáctica y semántica los que borran en una primera lectura las demás caras del texto: la asociación oximórica de los contrarios, la dimensión enigmática sugerida por las metáforas. Por eso no se da aquí el carácter de violencia propio del fragmento valentiano, siempre más concentrado, más elíptico, indeterminado y por lo tanto enigmático, no sólo en Treinta y siete fragmentos sino en toda su obra. Desde $A$ modo de esperanza, Valente empieza a practicar el fragmento ${ }^{6}$, como se comprueba con el poema «El circo: cinco fragmentos» (Valente, 1980: 50), si

\footnotetext{
${ }^{6}$ Igualmente reflexionó acerca de esta modalidad creativa en varios textos, entre los cuales uno es relevante por acercarnos a la obra de José Lezama Lima: hizo de prólogo a Juego de las decapitaciones que se publicó en 1982. El
} 
bien la retracción y condensación no aparecen todavía en su plena potencia para crear un choque con la lógica como será el caso luego en El fulgor:

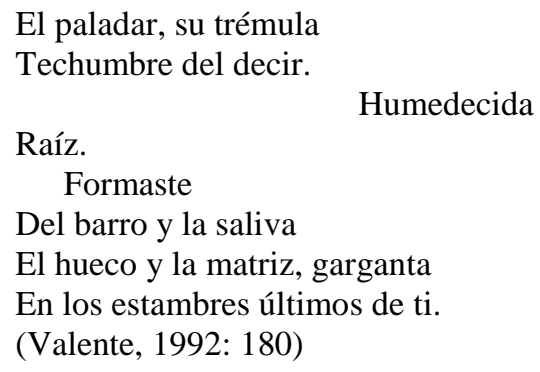

Valente retoma el fragmento y lo reescribe en el poemario siguiente Al dios del lugar (Valente, 1992: 191) acentuando lo concentrado y elíptico (suprime cuanto sea demasiado explicativo o anecdótico), haciéndolo así más enigmático, entre erótico y metapoético:

Formó
De tierra y de saliva un hueco, el único
Que pudo al cabo contener la luz.

(Materia)

Si consideramos Fragmentos de un libro futuro, nos encontramos ante un entramado textual hecho igualmente de narratividad y meditación, en el que predominan los fragmentos, algunos breves y hasta muy breves que son islotes en la página blanca. Funcionan a la manera del rayo que deslumbra, iluminando y cegando a la vez: «Incorpóreo, cela en la nuca el ángel toda su luminosidad» (16), «Caer en vertical. Sueño sin fin de la caída. Qué repentina formación el ala» (12). No obstante la presencia de esta forma poética, se puede notar que la indeterminación no es tanta como en los poemarios anteriores: la presencia de un yo enfrentado a su finitud, conversando con ella o meditando sobre ella, reintroduce una dimensión elegíaca poco frecuente (Valente, 2000: 75):

La agonía, la muerte, el pavo,

Vocea el vendedor de lotería.

Esos nombres son cifras de la ciega alegría

Que al término me lleva y ciego en él me acabo.

(Valleinclanesca)

La inflexión (por motivos claramente biográficos) se nota en la presencia de varios fragmentos de tonalidad similar. Al lado de algunos poemas narrativos como el homenaje a Cernuda (28) o a Lorca (49), convertidos ambos en futuro y memoria colectivos, se suceden una mayoría de textos meditativos, elegíacos, de forma fragmentaria, dedicados muchos de ellos tanto al hijo como al yo lírico que se identifica con el hijo muerto, confundiéndose las dos muertes $(11,14,22,24,36,48,52$, $54,65,79 \ldots)$. Sigue presente no obstante una marcada dimensión intertextual ${ }^{7}$. con referencias o

título sugestivo «El pulpo, la araña y la imagen» anuncia la reflexión sobre la tensión entre centro y dispersión o sea fragmentos (Valente, 2004: 17-21).

${ }^{7}$ Las referencias vienen aclaradas por ser también los textos expresión de admiración, homenajes (cobrando así lo intertextual una forma peculiar), cuando en la obra anterior no solía explicitar Valente el recurso a la intertextualidad, 


\section{Andrés Sánchez Robayna: El libro, tras la duna. Diálogos con J. Á. Valente e Yves Bonnefoy}

reescrituras («versiones»), o la vertiente de la intermedialidad (Ucello, 44-45; Bacon, 68; Egon Schiele, 94), o metatextualidad (98), características compartidas ampliamente con el libro de Sánchez Robayna

La tensión en el poemario de Valente se da entre la omnipresencia de la muerte como término de un trayecto -en ese sentido nos encontramos ante un testamento poético: «Y todos los poemas que he escrito / vuelven a mí nocturnos» (98)- y una apertura al futuro que estriba en la fe en la palabra como alumbramiento. Podemos comprobar cómo son los dos últimos poemarios los que indican el poder iluminativo de la poesía: el penúltimo del que sólo cito los versos finales, «Sombra. / Pero tú aún ardes luminoso» (101), y el último en forma de haiku:

Cima del canto
El ruiseñor y tú
Ya sois lo mismo.

(Anónimo: versión)

Si el yo, al hacer una especie de balance, concluye «Andamos para nunca llegar» (100), es posible leer aquí no un fracaso sino la afirmación de una continuación sin fin de la palabra poética en el libro futuro, en los libros futuros infinitamente por escribir.

\section{Lo inacabado y la totalidad}

Escoger el fragmento, postula acertadamente José-Miguel Ullán, es manifestar «[...] la arrogancia de lo inconcluso, la euforia de las chispas contra la tiranía de la plenitud» (Ullán, 1992: 20). Tanto Valente como Sánchez Robayna han hecho la elección de una poética de lo fragmentario; significa optar por un arte de la disconformidad frente al canon entendido como sistema, si bien se sabe que lo rupturista puede acabar convirtiéndose en canónico ${ }^{8}$. En el caso de Valente, fue una opción de radicalidad ética que él mantuvo firme a lo largo de su vida y obra.

Recordemos que Valente, no sólo compuso un poemario dedicado enteramente al fragmento, 37 fragmentos, libro de 1971, sino que recurrió con auténtica constancia a esta forma que ya los románticos alemanes del grupo de Jena presentaban como un microcosmos. Tanto Schelling, Schlegel, como Richter (o Jean-Paul), Goethe veían en la forma breve del fragmento no una mutilación, tampoco una carencia, sino la posibilidad seminal de un todo. Valente lo manifestó al dar al poemario 37 fragmentos una conclusión abierta, y decirlo con este oxímoron da cuenta del carácter de este libro concebido ante todo como opera aperta, obra en perpetuo devenir, inscrita en un movimiento incesante:

\footnotetext{
siendo ésta a menudo vehículo y objeto de ironía, sarcasmo o subversión. Por su parte, Sánchez Robayna quiso añadir notas que aclararan las referencias. La traducción y edición bilingüe hecha por Claude Le Bigot las retoma al igual.

${ }^{8}$ Ambos se sitúan dentro de la Modernidad, concebida como la herencia del cruce entre lo sensible y lo especulativo que arranca del XVIII (o sea el momento de emergencia de la estética que se va emancipando de las autoridades) pasando por el momento clave de las vanguardias históricas. Valente lo dejó claro, entre sus muchos textos, en el artículo publicado en 1995 en la Revista de Occidente, «Cuatro referentes para una estética contemporánea» (Valente, 2002: 103); Robayna lo apunta hablando del «[...] territorio para mí tan próximo y querido, de la intersección de poesía y pensamiento que, desde fines del XVIII hasta el presente, marca a un sector preciso de nuestra modernidad» (Sánchez Robayna, 2011: 10).
} 


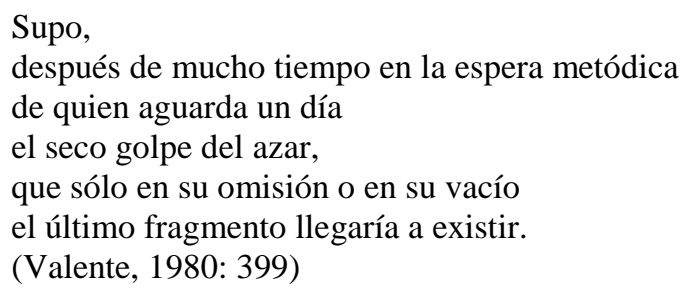

Valente lo plantea igualmente en sus ensayos, en sus estudios sobre las artes ${ }^{9}$ : así en el artículo sobre la pintura de José Manuel Broto «[...] Sólo el fragmento remite o alude a la totalidad y sólo esta alusión hace existir a aquélla.» (Valente, 2002: 147).

Acerca de eso, cabe precisar que lo inacabado no se puede entender como incompletud. Tanto el fragmento metapoético como el ensayo en Valente aclaran la relación fecunda entre el vacío, u omisión, elipsis, y la creación: aquellos son la condición de ésta. El fragmento más que incompleto es una forma inacabada. Lo incompleto manifiesta más bien una carencia o falta, cuando al revés lo inacabado, por su dimensión elíptica, deja entrever la totalidad, la anuncia o la sugiere. Corresponde a la concepción que Valente tiene del fragmento y enlaza con el pensamiento oriental del arte que privilegia el misterio, o la interrupción del trazado en pintura, descartando lo acabado, recurriendo a lo discontinuo para que el cuadro siga vivo y no inerte.

Esta misma potencialidad de evolución del no ser hacia el ser está inscrita en la pintura ${ }^{10}$ aparentemente sin acabar que se le presenta al emperador chino Hui-Tsung en uno de los apólogos de La fin de l'Âge d'Argent ${ }^{11}$ (Valente, 1992) solo un rincón está pintado con suma exquisitez y precisión extremada. El ave y la flor son indicaciones, guías para encontrar lo que está en ciernes, o por advenir. Por eso mismo está la pintura viva y llena de energía, encierra movimiento y dinamismo; el cuadro completo y total está formándose a partir del mero fragmento de pintura; y como se postula conclusivamente: «Signaler un coin est déjà suffisant, à ce que Hui-Tsung savait de Confucius. Pour ceux qui ne pourraient trouver les trois autres il serait vain de se répéter» (Valente, 1992: 103). Valente compara el poder de iluminación del fragmento con el de la pintura china en que

\footnotetext{
${ }^{9}$ Harto conocida es la relación de Valente con las artes y con los artistas con los cuales no dejó de dialogar tanto en la vida como en sus ensayos de estética y sus poemas. Mantuvo Valente una interrogación constante sobre la creación nacida de una materia única; de ahí la intensidad de su diálogo tanto con Eduardo Chillida, Antoni Tàpies, Luis Fernández y otros muchos creadores (Rebeyrolle, Baruj Salinas, Tobey). Por ello, las galerías de arte a raíz de exposiciones le pidieron prólogos para los catálogos. Los archivos de la Cátedra Valente que dirige Claudio Rodríguez Fer en Santiago de Compostela dan fe de tal nutrida y fecunda conexión con la expresión artística. De ahí que el logo de la Cátedra sea de la mano del propio Tàpies y haya allí muchas obras de arte.

${ }^{10}$ Dentro de este estudio no cabe analizar los cruces entre los tres poetas acerca de las artes; sus respectivos ensayos son indudablemente esclarecedores en cuanto a las apuestas del arte, y más allá aclaran su propia poesía. La escritura ensayística hace de introducción y guía, funciona como exégesis de sus poéticas respectivas.

${ }^{11}$ Cito aquí la traducción al francés para recordar la historia violenta de este libro de relatos breves. Cinco de estos relatos fueron publicados en 1971 en Las Palmas de Gran Canaria en Número trece, pero uno «El uniforme del general» fue censurado, se destruyeron los ejemplares de Número trece y se organizó un proceso ante un tribunal militar contra los editores y el escritor. Caso excepcional en la posguerra de procesados por un consejo de guerra. De modo que el libro se publicó incompleto y por etapas sucesivas. El fin de la edad de plata apareció en edición parcial por primera vez en España en 1973 en la editorial Seix-Barral, luego Jacques Ancet lo tradujo y lo publicó en 1992 en José Corti en París, incluyendo pues el texto censurado. Fue sólo en 1995 cuando salió completo en España publicado por Tusquets bajo el título El fin de la edad de plata, seguido de Nueve enunciaciones. Todos los pormenores del acto de censura y condena, tanto del editor canario como de J. Á. Valente están en Valente vital (Rodríguez Fer, 2014: 236-255).
} 
la figura no es central para poder crear un dinamismo interno a la obra, un hálito que conduzca al centro. Detrás de lo que puede aparecer entonces como carencia, está la posibilidad de generar algo: por eso, hablando de la pintura china, dice Valente: «En la línea de esa aparente pobreza, que tiende al vacío como plenitud, se situaría la utilización del fragmento o de la figura descentrada como único signo posible de la totalidad» (Valente, 2002: 147).

Presentando un corpus de textos teóricos sobre la pintura china, François Cheng señala como la tradición en China funciona sin ruptura, siendo una auténtica cadena de transmisión: «[...] un système qui procède par intégration des apports successifs» (Cheng, 1989: 13). En ese sentido, la forma artística aparece siempre inconclusa, orientada hacia lo que está por aparecer, hacia la forma futura, concepción que remite al mismo título del poemario último de Valente. Al comentar Material memoria, poemario valentiano compuesto también de fragmentos, observaba el propio Sánchez Robayna:

\footnotetext{
Una particular propensión al texto de fría rotundidad expresiva en la que caben -sin contradicciónnitidez y ambigüedad, rasgos que hacen recordar lo que un pintor, Kandinsky, aplicó al cuadro -el cuadro como copa glacial- al intentar definir el movimiento de lo informe hacia la forma (Sánchez Robayna, 1995: 187-188).
}

El estudio filológico de Sánchez Robayna pone de relieve lo propio y singular de esta modalidad de creación: su dinamismo interno volcado hacia la manifestación que está por venir asî como el pintor Kandinsky lo teorizó en su ensayo ${ }^{12}$. Walter Benjamin postuló que el fragmento de la ánfora tiene el poder de sugerir lo que es la ánfora en su totalidad (Benjamin, 1991: 58), o sea que la completud se construye por un movimiento interno que parte de lo inacabado, es decir cuando se deja un espacio libre, desocupado. Valente lo desarrolla en varios textos, evocando: «[...] el espacio vacío del que habla Heidegger en el texto que escribió sobre el espacio y el arte. Es el lugar de la manifestación, el lugar donde puede manifestarse algo»(Valente, 2002: 127). Igual observación merece lo que se ha dado en llamar silencio en la poesía y que deriva del discurso en forma de fragmento, o fragmentado, incluso fragmentario. Se suele asociar fragmento con silencio (o vacío), lo propio del silencio y fragmento es captar lo sensible mediante la intuición, captar lo que se le escapa a la comprensión racional o lógica. En ese sentido, manifiesta el fragmento cierto fracaso de la racionalidad, muestra los límites de las facultades llamadas intelectivas. El filósofo Marc Jimenez lo apuntó al decir: «Le fragment est un défi à la pensée systématique, à l'impérialisme de la pensée déductive et organisatrice. Le fragment est en effet comme un grain de pollen chargé de semer la vérité» (Jimenez, 1997: 179).

Marca este elemento una constante de la obra valentiana que se manifiesta hasta Fragmentos de un libro futuro. En este aspecto, converge hacia el pensamiento de Bonnefoy que expresó en

\footnotetext{
${ }^{12}$ En su ensayo de 1912, Du spirituel dans l'art et dans la peinture en particulier, postuló Kandinsky la autonomía de la obra, lo cual suponía una vida, una energía interna a la creación: «[...] l'œuvre d'art véritable naît de 'l'artiste'. Détachée de lui, elle prend une vie autonome, devient une personnalité, un sujet indépendant, animé d'un souffle spirituel, qui mène également une vie matérielle réelle -un être.» (Kandinsky, 1912: 197).
} 
varios textos (ensayos, discursos, entre los cuales su discurso sobre el haiku) sus reparos y críticas hacia el concepto por su capacidad de esterilización de la palabra y de ceguera frente al ser.

\section{El diario-testamento poético, el diario vital y metapoético}

Las circunstancias biográficas como históricas influyen obviamente en ambos libros. En el caso de Sánchez Robayna, el lector acompaña a un yo lírico en su recorrido vital, personal (la ida a Barcelona, la formación universitaria en Barcelona, la iluminación del amor, del hijo), es un recorrido a veces contextualizado históricamente (la muerte del dictador, mayo del 68), a menudo mediante textos narrativos, casi anecdotizados, que se cruzan con fragmentos de meditación, interrogación o iluminación metapoéticos. La indagación acerca de la palabra poética corre pareja con el fluir temporal, la vida cotidiana o el paso de la historia. De modo que los críticos no dudan en calificar el largo poemario de autobiografía poética. Lo cual por supuesto no agota el significado del libro ni su alcance, pero sí permite dar cuenta de una de sus dimensiones quizás más evidentes y claras. Cabe precisar que si el eje personal permite estructurar claramente el largo poema robayniano, nunca desaparece la preocupación por la alteridad. Las experiencias, las lecciones y los conocimientos que se nos cuenta el yo lírico cobran un alcance que desborda lo estrictamente personal para llegar al ser humano. Propone una lectura y un continuo cuestionamiento del mundo lo mismo que constituye una «decantación última de una poética que ha ido gestándose a lo largo de más de tres décadas» (Ruiz Casanova, 2012: 48). Ahora bien, es esta presencia de un yo personal en El libro, tras la duna ${ }^{13}$, la que señala una diferencia con la obra valentiana más decididamente orientada hacia la disolución del yo lírico, hasta el «deshacimiento» para decirlo en clave valentiana (Valente, 2000: 77). Y de hecho fue una dimensión a la que Sánchez Robayna dedicó estudios, observando la desaparición de todo lirismo en Valente por recusar éste la concepción de un yo «absoluto que aguanta todo el peso expresivo». (Sánchez Robayna, 1995: 174). La postura de José Ángel Valente no cambió a lo largo de su creación, desde la suma poética Punto cero que recopila 26 años de escritura en la que procede sistemática y radicalmente a la aniquilación tanto de la figura del autor como de la del yo lírico, hasta los libros siguientes. El lector de Valente ha de asumir la desaparición del sujeto lírico como condición de «la infinita libertad». El epígrafe que abre Punto cero lo postula de modo tajante: «La palabra ha de llevar al punto cero, al punto de la indeterminación infinita, de la infinita libertad» ${ }^{14}$ (Valente, 1980). No deja Valente de volver a reivindicar tal postura en los sucesivos escritos, sea mediante los sarcasmos que lanza contra los poetas venales o que van en pos de la fama, «Danza / oso de cualquier zíngaro» (Valente, 1980: 394), sea elogiando a Rimbaud y Lautreamont en el poema «Punto cero» (Valente, 1980: 369), sea

\footnotetext{
${ }^{13}$ Otra diferencia radica en el anclaje de toda la poesía robayniana en un entorno natural marcadamente insular, sea la isla metafórica (isla como fragmento, palabra) y/o referencial (Canarias, Cuba...).

${ }^{14}$ A lo cual se añade la ironía propia de Valente al presentar la cita como sacada de un supuesto 'diario anónimo', jugando con la trillada tradición del manuscrito encontrado. Ahora cabe ver que el último poema de Fragmentos se presenta también como anónimo, marcando así una continuidad evidente.
} 


\section{Andrés Sánchez Robayna: El libro, tras la duna. Diálogos con J. Á. Valente e Yves Bonnefoy}

invitando a recurrir a la falsificación autobiográfica, «Autobiografía», «Criptomemorias» (Valente, 1980: 411). Es un rechazo sin concesión alguna de cualquier figura que no sea la de la palabra formándose y a punto de aparecer, que no sea la de una lengua purificada para la tribu. El lugar del canto para Valente es el desde donde se rescatan las palabras cristalizadas por los poderes y las oligarquías. Es un elemento que la crítica suele situar sólo en los primeros poemarios de Valente cuando en realidad la preocupación por la 'Cité' nunca desapareció en él ${ }^{15}$. En Fragmentos de un libro futuro, es relevante ver que la expresión del disenso sigue presente como lo muestra el que el penúltimo poema esté dedicado a una figura mayor de la heterodoxia, Giordano Bruno ejecutado en la Piazza, Campo dei Fiori, en 1600: «Pero tú aún ardes luminoso» (Valente, 2000: 101).

\section{La roca y la piedra}

La obra de Sánchez Robayna anterior a El libro, tras la duna marca cómo la roca, la piedra en sus formas diversas, o sea la naturaleza propia de la insularidad canaria nutren su sensibilidad y su imaginario. Las múltiples entrevistas dan cuenta de ello hasta el punto de conceder el poeta que existe una «una poética insular» (Arjona, 2009) vinculada con una luz propia y una naturaleza singularmente impactante. Por su parte, Bonnefoy meditó frente a los Tombeaux de Ravenne (Bonnefoy, 1992), intentando ver y sentir en estas piedras heredadas del pasado, la manifestación de una presencia humana, espiritual y sensible a la vez. Bonnefoy lamenta que la tradición filosófica no haya sabido considerar la piedra en sí, haya olvidado por no mirarlas con suficiente atención, las piedras de las sepulturas de Ravenne: «L'esprit qui s'interroge sur l'être, mais rarement sur la pierre, s'est détourné de ces pierres qui sont ainsi deux fois abandonnées à l'oubli (Bonnefoy, 1992: 13)». Afirma así su voluntad de interrogar la piedra para captar lo real descartando cualquier aproximación por el concepto y desconfiando de la imagen que pudiera ocultar lo que nombra. Encierra la piedra, postula él, cuando se la contempla, el poder de abrir horizontes, abrir puertas a lo real, un real en que vida y muerte son una misma cosa. Por eso al mirar con intensidad los motivos grabados en las sepulturas de Ravenne (en particular una vid), exclama Yves Bonnefoy:

On sent inépuisable cette vigne, où indiscernablement le cœur vient puiser la gloire de vivre et l'enseignement de la mort. Telle est la pierre. Je ne puis me pencher sur elle sans la reconnaître insondable, et cet abîme de plénitude, cette nuit que recouvre une lumière éternelle, c'est pour moi le réel exemplairement. Orgueil qui fonde ce qui est, aube du monde sensible ! Ce qui est tracé dans la pierre existe, au sens pathétique et plus fort de ce mot (Bonnefoy, 1992: 18).

\footnotetext{
${ }^{15}$ Con el poema «Sobre el lugar del canto», afirma Valente su plena solidaridad con los que denunciaban las mentiras del momento histórico que les había tocado vivir. Por eso concluía el poema con fuerza tajante: «Ésta es la hora, éste es el tiempo / -hijo soy de esta historia- / éste el lugar que un día / fue solar prodigioso de una casa más grande.» (Valente. 1980: 127). La dicción hecha de deícticos del presente y hecha también de intertextualidad machadiana como quevediana traduce que pertenece el poema a la etapa inicial de Valente. El que el texto siguiente se llame «La ciudad destruida» confirma que estamos en la fase del necesario destruir propio del libro Punto cero. Sería erróneo pensar que tal postura se limitó al momento del nacional-catolicismo, los libros Valente vital que publicó la Cátedra Valente de Poesía y Estética dan fe de lo contrario, lo mismo que las Obras Completas que recogen los escritos cívicos, polémicos sobre temas de la 'Cité'. El marcado interés de Valente por los místicos se debe a su condición de heterodoxos que cuestionan el dogma, la letra.
} 
Los poetas Bonnefoy y Sánchez Robayna miran la piedra o la roca, lo mineral en sus múltiples formas (duna, desierto, arena, casa pueblerina), las formas primeras del mundo natural para sentir cómo la percepción de su inmediatez se anuda a su propio exitir, les permite acceder a una forma de liberación de lo estrictamente conceptual. Bonnefoy la designa como «le vrai lieu» (1992: 22) lejos del puro concepto que encierra cual una cárcel. «Lieu» o lugar que siempre es un aquí, con el valor de inmediatez que encierra este deíctico: supone el reconocerse en el lugar, el sentirse parte de un universo que se está ordenando, equilibrando, reconciliando al volver a unificarse, a ser uno. Se trata pues de la aprehensión de un cosmos en el pleno sentido de la palabra. El sujeto lírico del poema robayniano, al contemplar el mundo nocturno, el cielo de la noche, se encuentra y se siente vivir a la par que se va fundiendo en el cosmos, se va haciendo cosmos en un movimiento de reunificación de lo escindido:

\footnotetext{
Las palabras que a veces pronunciamos

De gratitud, de reconocimiento por la presencia viva o la conciencia de respirar bajo la noche abierta, noche branquial que a todos nos respira como nosotros a ella, noche en la que somos entregada noche y en la que ruedan astros y palabras. (Sánchez Robayna, 2012: 152)
}

La epífora de la palabra «noche» (que funciona también como epanadiplosis) da cuenta visual y musicalmente de la unión casi erótica entre el sujeto lírico y el lugar. Observemos también cómo la expresión «noche branquial que a todos nos respira» recuerda este otro verso, «El arquero / no respiraba: él era el respirado» (Sánchez Robayna, 2012: 240). Tales versos, entre otros muchos, hacen eco a la fusión de los cuerpos particularmente celebrada en el poemario Mandorla de Valente donde la vertiente erótica cobra un protagonismo marcado; bien se sabe cómo la mandorla tiene valor místico por ser la forma en la que se circunscribe la figura de Cristo, y es a la par representación erótica por figurar el sexo femenino: «Me respiraste / en tu vacío lleno / y yo latía en ti y en ti latían / la vulva, el verbo, el vértigo y el centro» (Valente, 1992: 97). Valente postuló el poder unitivo del acto sexual tanto en sus poemas como en sus ensayos, si bien se nota cierta inflexión al final de la obra por motivos biográficos ${ }^{16}$.

La mineralidad en su forma de roca o de piedra cobra protagonismo en la obra de los tres poetas como emblema de lo efímero de la vida humana, de las inscripciones en las losas:

\footnotetext{
${ }^{16}$ La inflexión, por decirlo de cierto modo, se da principalmente a partir del poemario No amanece el cantor enteramente dedicado al hijo muerto (si bien no se dice claramente aquello), herida nunca superada por el poeta. No obstante, cabe observar que el tema de la droga aparece anteriormente en poemas de El inocente y de Material memoria lo mismo que en artículos que redactó el poeta. Entre la serie de libros editados por la Cátedra J. Á. Valente de Poesía y Estética bajo el título de Valente vital, el dedicado a la vivencia de Valente sucesivamente en Ginebra, Saboya y París, aclara este punto preciso. (Rodríguez Fer, 2014: 341-356). En cuanto al tema de Eros, la evolución se da en Fragmentos...: en este último poemario el yo lírico se vuelve elegíaco al evocar la perdida relación erótica: «Vacío. / No tener, / no sentir el calor de tu cuerpo». (Valente, 2000: 99). La proximidad de la propia muerte y la degradación del cuerpo vienen lógicamente a producir efectos en el tono del libro.
} 
"Une Pierre"

Il désirait, sans connaître,

Il a péri, sans avoir.

Arbres, fumées,

Toutes lignes de vent et de déception furent son gite,

Infiniment

Il n'a étreint que sa mort

(Bonnefoy, 1982: 204)

Sánchez Robayna y Bonnefoy se muestran atentos a captar la presencia o inmediatez de las cosas, captar la esencia de la piedra o de la duna, incluso o precisamente de las cosas más sencillas y humildes, cuando Valente hace de la piedra un símbolo relacionado con la mística, se hace patente aquello tanto en los poemas como en el ensayo La piedra y el centro. En su poesía, no es la piedra sino el cuerpo en tanto que materialidad sensible el que da entrada a lo real y lo espiritual conjuntamente.

La piedra en Valente remite a los monasterios, los desiertos, como espacios de recluimiento y aislamiento voluntarios con la finalidad de centrarse en lo más esencial, encontrar una respuesta al enigma de la vida y del mundo, conocerse. Es espacio que permite deshacerse de su personalidad empírica, metaforiza el exilio y la mirada hacia la página en blanco cuando se espera el advenimiento de la palabra porque «Escribir no es hacer, sino aposentarse, estar» (Valente, 1992: 115). De ahí que se encuentre Valente con el misticismo, y tal es el contenido del ensayo valentiano dedicado a pensamientos, figuras, cuestiones en relación todos y todas con lo que se designa como la mística: pensar la relación con lo que pueda denominarse dios o el verbo. Valente dedicó su ensayo La piedra y el centro a pensar la escisión del lenguaje y de la cosa, y concibió la mística como vía de acceso a aquella unidad perdida asociándola a la carne: «La abolición de la dualidad cuerpo-espíritu es sustancia de toda mística» (Valente, 1991: 39). El título del ensayo reúne en un gesto que parece paradójico la piedra -forma natural, cosa concreta que supone la falta de vida, la dureza y el peso-, y una noción, un elemento abstracto por pertenecer al campo de la geometría y la filosofía. Valente partiendo de la copla «Fui la piedra y fui el centro», definió la división del universo como «desgarramiento de lo uno» concluyendo que «La piedra y el centro son, en verdad, lo mismo» (Valente, 1991: 17).

Captar lo inmediato es sentir a la par la vida y la muerte, es asumir lo efímero de la vida humana también. Tal conciencia de la finitud se expresa en El libro, tras la duna como lo subraya la crítica que ve en ello la causa de la tonalidad elegíaca del libro. Según José Francisco Ruiz Casanova, «el tono elegíaco de su poesía [es] el que va a presidir, de forma diáfana, sus versos desde El libro, tras la duna hasta el presente.»(Ruiz Casanova, 2012: 46). De hecho, la conciencia temporal, o sea del ser como tiempo es ineludible a lo largo del trayecto del yo poético. El pensamiento sobre el tiempo y por lo tanto la finitud del hombre toma la forma de un caminar, propio y colectivo a la vez (observemos que el nosotros nunca desaparece del todo si bien el yo está muy presente). 
Pese a ello (o quizás por ello mismo), se puede sentir en el libro una tonalidad exultante, gozosa. La percepción de lo inmediato del mundo, precisamente por ser éste pasajero y huidizo, cobra más valor y lo va celebrando el yo casi en forma de himno. Celebra la melodía del universo, llamándola como «el secreto / silabario del cielo» (64), o «la música del mundo» (82), pasando por un ritmo repetivivo y dinámico $(50,52)$, por un juego intenso de aliteraciones (64) o asonancias (62), por exclamaciones hímnicas: «Oh desasida claridad» (62), «iClaros astros / y palabras fundidos en abrazo!» (178), ejemplos éstos de modalidades diversas que expresan una captación no intelectual ni racional sino sensitiva de los elementos naturales. De modo que se desprende una fuerte exaltación ante ellos que traduce un anhelo de fusión, el deseo casi físico de entrar en ellos para conocerlos. Bonnefoy evoca la aproximación a «la substance des choses, à l'intuition de leur épaisseur qui excède l'intelligible [...]» (Bonnefoy, 2009: 332) como si fuese una experiencia erótica, tal como lo significa el verbo conocer en la Biblia. Igualmente vemos en la poesía de Bonnefoy cómo se intenta sentir la presencia del mundo natural en sus cosas más sencillas y humildes, cómo el sujeto lírico quiere recuperar un lugar propicio a la alteridad, lugar alterado, oscurecido o empobrecido por el concepto y la prepotencia del intelecto. Al resumir el proyecto poético de Bonnefoy, Claude Esteban habla de su lucidez y vigilancia al querer aproximarse a lo íntimo de las cosas, sentir la epifanía de su presencia (término éste central en la poética de Bonnefoy):

Tout le travail de l'écrivain chez Bonnefoy, par le truchement du poème, mais aussi bien par la réflexion sur les images et les formes artistiques, depuis Les tombeaux de Ravenne, voici bientôt cinquante ans, jusqu'aux études récentes sur Mondrian et Picasso, oui, ce travail lucide témoigne d'une singulière vigilance à restaurer la valeur d'un geste, d'un regard, d'une subjectivité qui s'assume comme telle, dans l'approche de cette "réalité rugueuse" qui nous sollicite et nous échappe, ici et maintenant, au plus intime du quotidien (Esteban, 2003: 8).

Quizás en este punto podamos observar matices con la obra valentiana, relativamente poco atenta a las cosas mismas, si bien un texto como «El cántaro» puede dar muestra de sensibilidad a lo más humilde y cotidiano: «suprema / realidad de la forma, / creado de la tierra» (Valente, 1980: 106). Sin embargo, este poema se desvía y decanta rápidamente hacia una reflexión metapoética, que parece primar sobre el objeto, reduciendo su potencialidad de encarnación e inmediatez, y de hecho, así lo interpretó la crítica: «El hondo cántaro / de clara curvatura / bella y servil: / el cántaro y el canto» (Íbid.). Pues precisamente, al estudiar Sánchez Robayna en los años noventa dos poemas de Valente, se interrogaba observando la primacia absoluta de la anonimia en los textos, se hacía preguntas sobre la exorbitante preferencia otorgada a lo que designaba como «la impersonalidad»: «La anonimia es si se quiere, el otro nombre de una impersonalidad» (Sánchez Robayna, 1992: 44). En este artículo breve, el filólogo se mostraba sensible al pensamiento de Maurice Blanchot, pensamiento en que domina la negatividad derivada de la estética mallarmeana conducida a sus extremos, o sea una absolutización de la Palabra (lo que para Bonnefoy fue el motivo del fracaso ${ }^{17}$ de

\footnotetext{
${ }^{17}$ Emplea Bonnefoy la palabra evocando la angustia sin asumir de Mallarmé ante su sueño imposible de la Obra total y la esperanza de conseguirla, comentando que solo en una carta a Verlaine llegó a evocarlas (Mallarmé, 1995: 27).
} 
Mallarmé). Sánchez Robayna acerca este planteamiento al epígrafe de Punto cero: «La palabra ha de llevar al punto cero, al punto de la indeterminación infinita, de la infinita libertad» (Valente, 1980) comentando en particular la voz «indeterminación» ${ }^{18}$. Es irrenunciable en Valente la marcada preocupación de anonimato, la cual se expresa en poemas iconoclastas en un primer sentido, (quiebra la imagen propia que le devuelve el espejo) y por supuesto cualquier expresión de un yo solipsista ${ }^{19}$. Heredero de las vanguardias históricas, Valente rehúye de lo biográfico asimilado a lo anecdótico cuando para Bonnefoy decir 'yo' no supone egotismo, ni excluye la alteridad, sino que intenta situar al ser en el mundo mediante la poesía para, a pesar de la opacidad fenomenológica y la arbitrariedad lingüística, intentar sentir el mundo, ser parte de él. Decir yo sería pues dejarse ir hacia el mundo visto y sentido como «proximité radieuse préalable qui nous attend» (Munier, 2003: 42). Semejante postura se desprende de El libro, tras la duna en el que el universo parece una promesa para un yo que lo espera y contempla:

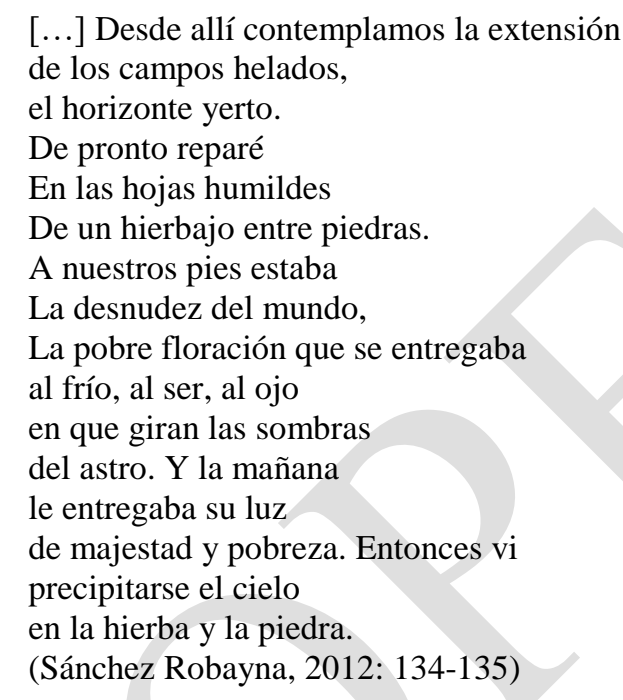

Este poema, por narrativo que sea, da a entender lo que Bonnefoy llama la intuición de la «présence», la cual opera una forma de comunión (diría un creyente) con el mundo, «l'adhésion» dice Munier (2003: 43). El poemario Les planches courbes (cuya publicación en 2001 levantó mucha expectativa en Francia) hace eco a este comentario de Roger Munier. Compuesto tanto de versos como de prosa poética, Les planches courbes celebran el universo, aceptando el yo su finitud y reafirmando su amor a las cosas primeras al término de un itinerario vital y poético. Proclama una forma de esperanza ${ }^{20}$ ante la evidencia del mundo.

Que ce monde demeure,

\footnotetext{
${ }^{18}$ Sugestiva aparece la propuesta del poeta y crítico peruano, Eduardo Chirinos quien, reflexionando acerca de la voz 'indeterminación', propone sustituirla por el neologismo 'indeterminancia' argumentando que elimina la carga de negatividad y subraya mejor «las múltiples posibilidades que resultan de su uso voluntario en la creación artística». Añade Chirinos que encima la 'indeterminancia' favorece la recepción activa del lector frente al silencio creado por ella. (Chirinos, 1998: 36).

${ }^{19}$ Por eso la cita aparece mencionada como sacada de un fingido Diario anónimo.

20 Jean-Michel Maulpoix lo recuerda y desarrolla en el estudio en línea que le dedica el poemario. Se publicó en $L a$ Quinzaine littéraire (15/11/2001), luego en el libro Adieu аи роѐme.
} 
Malgré la mort!

Serrée contre la branche

L'olive grise.

(Bonnefoy, 2001b: 25)

Itinerario y evidencia que Fabio Scotto glosa y analiza para poner de realce lo que significa escribir para Bonnefoy; sería

[...] un itinéraire et une itin-errance corporelle qui, loin de toute abstraction conceptuelle, immerge l'écriture dans la nature, jusqu'à rejoindre l'évidence, un terme dont la potentialité anagrammatique peut contenir aussi bien le latin videre (voir) que le français (é)vider. Comme si pour voir il fallait vider le monde de tout filtre intellectuel (Scotto, 2003: 127).

La indagación en el quehacer poético y la reflexión sobre la palabra llevan a Valente hasta el poemario dedicado a lo sagrado ${ }^{21}$ Tres lecciones de tinieblas (1980) cuya posibilidad de recepción es exigente; su lectura puede conducir al lector a concluir que la voz huye de lo sensible dejando la primacía al intelecto, impidiendo pues cualquier encuentro con lo inmediato ${ }^{22}$. Es indudable que este poemario opera un proceso de divinización de la Palabra: la Palabra, evocada como realidad sagrada y suprema, es la raíz de cuanto es y lo encierra todo en un movimiento perpetuo. Parece que lo inmediato del universo no se puede dar como tal, sin embargo cabe sentir cómo el texto se convierte en materia sensible, en tejido sonoro y rítmico al compás de la música que acompaña el rito ${ }^{23}$. Lo cual enlaza con la gran clave de la obra valentiana, el cuerpo. Si éste es Eros, tampoco se ha de olvidar que las realidades físicas -incluso las más triviales en un gesto de transgresión iconoclata (saliva, hedor, vómito...)- ocupan espacio en esta obra, siendo la mística otra expresión y manifestación como lo comentan los ensayos valentianos sobre el tema. Tanto Mandorla como El fulgor son pura celebración de la experiencia juntamente espiritual y erótica. Por eso es tan relevante constatar que lo inmediato, el mundo natural, aparecen en Fragmentos de un libro futuro. Si la evocación erotizada del Cabo de Gata (21) recuerda poemas de Mandorla, surgen en cambio versos otros y nuevos en que el yo contempla los elementos de la naturaleza ( «Al lento sol que baja hacia la tarde / ceder, abandonarse» (27). En el poema «(Parque de Figueras)» (Valente, 2000: 32) si bien se retoman motivos poéticos anteriores, («el descenso de la tarde, el canto del pájaro, el silencio»), éstos manifiestan una dimensión sensible fuerte que casi borra la simbólica o metafórica. Además se expresa el yo con un tono nuevo al evocar su contemplación casi serena en un texto próximo a la confidencia, entre personal y elegíaca:

Si hay un momento en el mundo

\footnotetext{
${ }^{21}$ Partiendo de la música sagrada compuesta por, entre otros músicos, Couperin y Delalande para un rito litúrgico de Semana Santa, Valente explora lo sagrado identificado con el alfabeto hebreo cuyas letras declina. La voz, según Jacques Ancet, se convierte en «à la fois souffle sonore et vocable antérieur à toute signification mais qui les contient toutes en germe» (Ancet, 1980: 22).

${ }^{22}$ En un estudio muy erudito y precioso, Carlos Peinado Elliot interpreta que «[...] el poeta (a imitación del movimiento creador del tsimtsum) se vacía de sí para acoger en su propio interior el universo» (Peinado Elliot, 2002: 407). Su trabajo hermenéutico da claves para entrar en un poema radical en el sentido primero de la voz.

${ }^{23}$ Como ocurre en la mayoría de los ritos sagrados (pero igualmente en los actos que congregan a las multitudes), estriba gran parte del poder del texto en las múltiples repeticiones invocatorias. El rito se dirige a los sentidos antes que a la razón.
} 


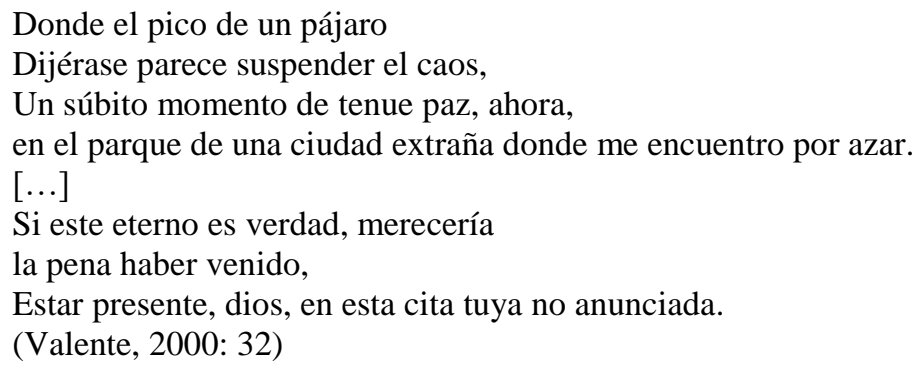

En cuanto al tema de Eros, igualmente aparece una inflexión: el yo lírico se vuelve elegíaco al evocar la perdida relación erótica: «Vacío. / No tener, / no sentir el calor de tu cuerpo.» (Valente, 2000: 99). La proximidad de la propia muerte y la degradación del cuerpo vienen lógicamente a producir efectos en el tono del libro, con lo cual a veces asoman versos que son confesiones y en que las voces («vacío» en el anterior ejemplo) cobran un significado lejos del horizonte de expectativa del lector valentiano.

\section{Duna, desierto y «vrai lieu»}

Ello porque imperó siempre en Valente una reivindicada preocupación de indeterminación que lo llevó a descartar en la mayor parte de su obra la representación o evocación del paisaje. Quizás sea el desierto con el cual inaugura sus publicaciones el espacio más emblemático desde el que se alza su voz: «Cruzo un desierto y su secreta / desolación sin nombre» (Valente, 1980: 13). Espacio eremítico y espacio exílico como otra metáfora de la creación. Valente se interrogó constantemente sobre el quehacer poético y emprendió una indagación de la palabra poética que descartaba cualquier elemento concreto e inmediato que no fuera la geografía erótica del cuerpo. Si algunos recuerdos relacionados con Galicia aparecen, se relacionan muy a menudo mediante la intertextualidad con la figura y la poesía de Rosalía de Castro (Breve son) y es principalmente en la obra en gallego, las Cántigas de alén editadas por Claudio Rodríguez Fer, donde el lazo con la tierra gallega y lo gallego se manifiesta de modo claro.

Por eso observa Claude Le Bigot lo que designa él como originalidad de Sánchez Robayna: «Mais ce qui fait avant tout l'originalité de son discours tient à l'ancrage particulier qu'il tire de l'espace insulaire canarien, à la fois comme référent géographique concret et comme espace mythique et fondateur de la méditation» (Le Bigot, 2012: 15). La insularidad (sea la de Cuba o de Grecia, etc.) como también el espacio barcelonés o el de otras capitales (París, Viena, Sevilla...) marcan las etapas del tiempo y las pérdidas que conlleva este fluir temporal. El espacio materializa la finitud y ofrece también un marco en el que vivir plenamente. Es lo que Bonnefoy, estableciendo una comparación entre Rimbaud y Baudelaire, postula: Baudelaire chocó con un límite (e incluso, según Bonnefoy, se dio cuenta de ello), el haber dejado de lado «une condition nécessaire à toute existence qu'on puisse dire réelle: l'acceptation du lieu et de la durée dans lesquels notre finitude s'incarne» (Bonnefoy, 2009: 435), cuando Rimbaud se entregó total y urgentemente a ello. Partiendo de tal observación se podría afirmar que El libro, tras la duna encierra la relación-confesión del narrador- 
yo lírico de ese caminar que lo llevó a aceptar al final estas coordenadas de la condición humana, y a someterse, sereno ya, a la prueba de los dados que ruedan:

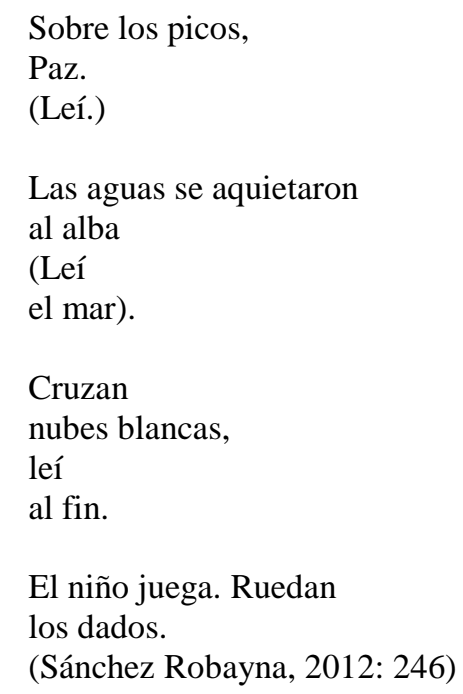

La metáfora de la lectura de la naturaleza se hace cada vez más intensa y precisa en las tres etapas estróficas, prescindiendo al final de los paréntesis y siendo el sintagma «al fin» expresión de un sentimiento de liberación. Se cierra aquí el ciclo iniciado en el poema de apertura con la figura infantil y los dados, inicio que el yo anunciaba con fórmulas, reiterativa la una y tautológica la otra, creando sentimiento de expectación y efecto de solemnidad:

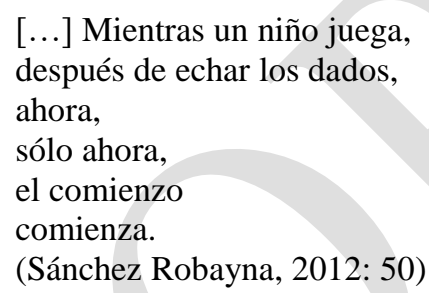

El eco entre los dos poemas, la continuidad evidente de los textos estructuran firmemente el poemario; ello y la construcción de un significado humano como metapoético hacen que El libro, tras la duna se pueda leer como el principio de una nueva aventura poética y vida personal siempre en busca de lo inmediato y trascendente a la vez. Laura López Fernández aclara que «Robayna sitúa lo transcendente dentro del nivel lingüístico del poema, que se convierte en el centro y el margen, en el punto cero, de partida y de llegada que genera las distintas dimensiones del poema» (López Fernández, 2000: 173). Con El libro, tras la duna, se puede apreciar cómo lo inmediato se nos da en una tonalidad menor porque humilde, más cerca de la dicción de Bonnefoy que de la de Valente; en éste asoma un decir corto y radical que nace de imágenes hechas de intensidad, fugacidad y violencia: 
(Valente, 1992: 30)

Sánchez Robayna lo apunta al escribir: «La poesía de Valente ha heredado una virtud que en español antiguo se llamaba recato; pero debajo de este cristal las palabras invaden el poema feroces, feraces» (Sánchez Robayna, 1996: 32).

\section{La palabra poética: ínsula extraña, «Une pierre» ${ }^{24}$}

Al evocar la insularidad de Andrés Sánchez Robayna, matiza Laura López Fernández el alcance de la palabra: «[...] esta insularidad, como he sugerido antes, va más allá de un mero referente geográfico y hay que entenderla como una propuesta estética» (López Fernández, 2000: 173). Obviamente hace falta ampliar este matiz a los poetas que comparten junto con Bonnefoy, Sánchez Robayna y Valente tal concepción estética ${ }^{25}$. La similitud de la metáfora de Char con la de Las ínsulas extrañas (título de la antología de 2000 propuesto por Valente, procede del poeta peruano Westphalen y, antes, de Juan de la $\mathrm{Cruz}^{26}$ ) no hace sino poner de realce una sensiblidad estética compartida. Ésta es la condición de posibilidad de diálogo.

Indudablemente no podemos sino apreciar cómo las reflexiones filológicas y posturas estéticas de los tres creadores convergen y se cruzan, cómo comparten ellos concepciones próximas en el campo del pensamiento literario, poético y estético. Su concepción de la poesía es estética y crítica, ven ellos la poesía como espacio de indagación y renovación de la lengua, y en ese sentido es ética porque a ella le toca el deber que Bonnefoy resume así: «[...] disloquer les représentations du monde qui enferment la parole dans ce qui n'est de la réalité qu'une image» (Bonnefoy, 2003: 58) para que «les lectures conceptuelles s'effacent, dans l'ouvert d'une relation au monde» (Ibíd., 60).

Andrés Sánchez Robayna se ha convertido en uno de los críticos valentianos más pertinentes ${ }^{27}$, se puede apreciar cómo él y Valente dialogan entrecruzando sus reflexiones filológicas y estéticas, aportando material a la teoría literaria. De hecho hoy, parece muy lejana la época en que Luis Cernuda pudiera lamentar las carencias en su país del campo teórico: «un campo no cultivado entre nosotros» (Cernuda, 1958: 9) constataba él en Pensamiento poético de la lírica inglesa del siglo XIX, un ensayo precursor para lo contemporáneo. En efecto, tanto Valente primero como Sánchez Robayna luego, con acercamientos propios, contribuyeron -con otros muchos- a la edificación del corpus teórico de expresión española, pensando una poesía abierta, por ser exílica, liberada de

\footnotetext{
${ }^{24}$ En la primera sección de Les planches courbes, así se titulan nueve poemas, y se cierra el libro con poemas en prosa construidos alrededor de las piedras.

${ }^{25}$ En otro trabajo, tomé prestada de René Char su metáfora y título (Parole en archipel) para figurar así la concepción poética, estética y ética (el desierto o la insularidad como formas del exilio) de Valente y establecer una analogía entre su obra y un archipiélago.

${ }^{26}$ Valente había publicado ya anteriormente (1991) un texto sobre la obra de Juan de la Cruz titulado así. Está recopilado en La experiencia abisal (Valente, 2002: 70-73). También prologó la edición y traducción que Jacques Ancet hizo de la obra del poeta místico en 1997. En cuanto a la antología es obra de cuatro poetas-antólogos, dos españoles (Sánchez Robayna, Valente) y dos americanos (Milán, Varela). Su prólogo e introducción dejan bien clara la concepción que presidió a su elaboración.

${ }^{27}$ Culminó su trabajo de filólogo y crítico con la edición de las obras completas en Galaxia Gutenberg en los años 20062008.
} 
cualquier fosilización estética. Al decir de 'expresión española', se piensa aquí en la convicción afirmada en varias ocasiones por los dos críticos de que los poetas hispanoamericanos y españoles comparten un idioma común que conforma una suerte de lugar compartido; de ahí que concibieran una antología de poesía común a las dos orillas ${ }^{28}$ en la que afirmaran que «Para los hispano-hablantes -a pesar de las peculiaridades que conforman el mundo hispánico- la lengua es, verdaderamente, patria común» (Milán, Sánchez Robayna, Valente, Varela: 2002: 15). El repudio de una concepción historiográfica reducidamente nacional es un elemento central en los trabajos teóricos y poéticos de Valente y Sánchez Robayna, la introducción esclarecedora de Las Insulas extrañas lo demuestra con creces, así como esta reflexión meditativa de Valente:

Debo dejar Lisboa. ¿Dejarla? No podría. Hay lugares de los que no somos y a los que sin embargo pertenecemos. Abajo queda el río; arriba, el aire fresco o frío de un mayo marceante en la cima de todas las colinas luminosas (Valente, 2004: 135).

El criterio es el de una concepción estética y crítica de la poesía como espacio de indagación y renovación de la lengua. Fue la que presidió la creación de esta antología de 2000 tan debatida entonces -por pura incomprensión o rechazo dogmático- y tan necesaria para poder crear un espacio propicio a la epifanía de la palabra. Para Yves Bonnefoy, ésta solo puede ocurrir en que denomina un «vrai lieu» y que define en el célebre texto «L'acte et le lieu de la poésie»:

Et je suis prêt quant à moi à affirmer follement cet ici et ce maintenant qui sont déjà, c'est vrai, un là-bas et un autrefois, qui ne sont plus, qu'on nous a volés, mais qui, éternellement dans leur infirmité spatiale, sont le seul lieu concevable, le seul lieu qui mérite le nom de lieu. Il y a dans la poésie française moderne un cortège du Graal qui passe, les objets les plus vifs de cette terre -l'arbre, un visage, une pierreet ils doivent être nommés. Il en va de tout notre espoir. (Bonnefoy, 1992: 125-126)

Este lugar tambien viene creado por el diálogo que entablan los poetas superando las fronteras de los dogmas y de las culturas llamadas nacionales, emancipándose aquellos de éstas para liberar lo poético y hacer que sea una lengua compartida, palabras de la tribu. Los tres poetas comparten una concepción de la poesía como alumbramiento o présence de una realidad ignorada antes y que de repente se manifiesta en el espacio de la palabra permitiéndole al hombre conocer el mundo y llegar a ser.

\section{Bibliografía}

ANCET, J. (1998): «Rentrée en matière», en Trois Leçons de ténèbres suivi de Mandorle et de L'éclat. París, Poésie/Gallimard, NRF, pp. 7-33.

ARJONA, D. (2009): «Los insulares tenemos una 'pulsión del espacio' como frontera» en El Cultural; en http://www.elcultural.com/revista/letras/Andres-Sanchez-Robayna/25710 (última consulta, 19-05-17).

\footnotetext{
${ }^{28}$ El modelo anterior fue, como se sabe, la antología Laurel publicada en México en 1941. En la introducción, los cuatro antólogos lo recuerdan y reivindican claramente. Sánchez Robayna lo vuelve a postular en el texto escrito para los cursos de verano del Escorial de 2003, publicado luego en Poesía hispánica contemporánea: en él, precisa, matiza, argumenta y reivindica de nuevo el propósito de la antología de 2000.
} 
Benjamin, W. (1991): Ecrits français, 1933-1940. París, Gallimard, Folio/Essais.

BlESA, T. (2004): Tránsitos. Escritos sobre poesía. Valencia, Tirant lo Blanch.

Bonnefoy, Y. (1982): Poèmes. Du mouvement et de l'immobilité de Douve. Hier régnant désert.

Pierre écrite. Dans le leurre du seuil. París, NRF, Poésie/Gallimard.

- (1992): L'improbable et autres essais. París, Seuil.

- (1995): «L'unique et son interlocuteur» en S. MALlaRME, Correspondance. Lettres sur la poésie. París, Gallimard (1959, 1965-1985), pp. 7- 29.

- (2001a): «L'inquiétude de Shakespeare» en W. SHAKESPEARE, Romeo et Juliette. París, Gallimard/Folio, pp. 17.

- (2001b): Les planches courbes. París, NRF, Poésie/Gallimard.

- (2003): «Entretien» en Yves Bonnefoy, Europe, 890-891, pp. 49-63.

- (2009): Notre besoin de Rimbaud. París, Seuil.

- (2012): «Andrés Sánchez Robayna» en A. SAnChEz Robayna, Le livre, derrière la dune. Neuilly-lès-Dijon, Editions du Murmure, pp. 11-14.

CERnudA, L. (1958): Pensamiento poético de la lírica inglesa del siglo XIX. Madrid, Tecnos/Alianza, $2^{\text {a }}$ ed., 2002.

Cheng, F. (1989): Souffle-Esprit. Textes théoriques chinois sur l'art pictural chinois. París, Seuil, 2006.

ChIRINOS, E. (1998): La morada del silencio. Lima, Fondo de Cultura Económica.

Doce, J. (2013): Las formas disconformes. Lecturas de poesía hispánica. Madrid, Libro de la resistencia.

Doce, J. - SÁnchez Robayna, A. (2005): Poesía hispánica contemporánea. Barcelona, Galaxia Gutenberg.

EsteBAn, C. (2003): «Un paysage de pierres» en Yves Bonnefoy. Europe, 890-891, pp. 7-12.

Jimenez, M. (1997): Qu'est-ce-que l'esthétique? París, Gallimard, Folio/Essais.

KANDINSKY, W. (1912): Du spirituel dans l'art et dans la peinture en particulier. Trad. N. Debrand y B. du CRest, préface de P. SERs. París, Denoël, Folio/ Essais, 1989.

LE BigOt, C. (2012): «Dans la texture du temps» en A. SANChEZ RoBAYNA, Le livre, derrière la dune. Neuilly-lès-Dijon, Editions du Murmure, pp. 15-44.

LÓPEZ FERNÁNDEZ, L. (2000): «El esencialismo en la poesía de Andrés Sánchez Robayna», Anales de la literatura española contemporánea, Vol. 25, No. 1, Society of Spanish \& SpanishAmerican Studies, pp. 171-191; en http://www.jstor.org/stable/27741463 (última consulta, 2405-17).

LujÁN, Á. L. (2003): «El libro, de la memoria», Revista de libros, No. 82, Fundación Caja Madrid, p. 45; en http://www.jstor.org/stable/30230144 (última consulta, 24-05-17).

MaulpoiX, J.-M. (2001): «La voix qui espère. Yves Bonnefoy. Les planches courbes ». Blog J.-M. MAULPOIX; en https://www.maulpoix.net/bonnefoy.html (última consulta, 24-10-17). 
Milán, E. - SÁnchez Robayna, A. - Valente, J.Á. - VARela, B. (2000): Las ínsulas extrañas. Barcelona, Galaxia Gutenberg.

Munier, R. (2003): «L'infini de la finitude» en Yves Bonnefoy. Europe, 890-891, pp. 40-47.

PeinAdo Elliot, C. (2002): Unidad y trascendencia. Estudio sobre la obra de José Ángel Valente. Sevilla, Alfar.

RILKE, R. M. (1929): Lettres à un jeune poète. Trad. J. CALAS, F. LEPETIT, postface de J. VerAIN. París, Mille et une nuits, 1997.

Rodriguez Fer, C. (2002): «Introducción» en J. Á. VALENTE, Cuaderno de versiones. Barcelona, Galaxia Gutenberg, pp. 7-37.

- ed. (2014): Valente vital (Ginebra, Saboya, París). Universidade de Santiago de Compostela, Cátedra José Ángel Valente de Poesía y Estética.

SÁnchez Robayna, A. (1995): «La poesía de José Ángel Valente: suma de una lectura» en $E l$ silencio y la escucha: José Ángel Valente. ed. T. HERnÁndEZ FERnÁndEZ, Madrid, Cátedra/Ministerio de Cultura, pp. 187-188.

(1996): «Sobre dos poemas de José Ángel Valente» en J. AnCET, A. Ferrari, A. SÁnChEZ Robayna, G. AgAmben, J. JimÉnEZ, E. Lledó, en En torno a la obra de José Ángel Valente. Madrid, Alianza editorial, pp. 41-46.

(1999): «En favor de la complejidad», Revista de libros, No. 34, Fundación Caja Madrid, pp. 34-35; en http://www.jstor.org/stable/30229058 (última consulta, 24-05-17).

(2011): Cuaderno de las islas. Barcelona, Lumen.

- (2012): Le livre, derrière la dune. Préfacé par Y. BonnEFoY. Traduit et présenté par C. LE BIGOT. Neuilly-lès-Dijon, Editions du Murmure.

(2012): El espejo de tinta (Antología 1970-2010), ed. J. F. RuIz CASAnOvA, Madrid, Cátedra.

ScotTo, F. (2003): «Entre présence et disparition» en Yves Bonnefoy. Europe, 890-891, pp. 120-129.

Ullán, J.-M. (1981): «De la luminosa opacidad de los signos». Prólogo a J. Á. VAlEnTE, Noventa y nueve poemas. Madrid, Alianza Editorial, 1992, pp. 7-22.

VAlENTE, J. Á. (1980): Punto cero. Barcelona, Seix-Barral.

(1991): Variaciones sobre el pájaro y la red precedido de La piedra y el centro. Barcelona, Tusquets.

(1992): Material memoria. Trece años de poesía 1979-1992. Madrid, Alianza tres, 2a ed. ampliada, 1995.

- (1992): La fin de l'Âge d'argent. Traduction de Jacques ANCET. París, Corti.

- (2000): Fragmentos de un libro futuro. Barcelona, Galaxia Gutenberg. (2002): Elogio del calígrafo. Ensayos sobre arte. Barcelona, Galaxia Gutenberg. (2004): La experiencia abisal. Barcelona, Galaxia Gutenberg. 